\title{
Clinical Progress Note: Procalcitonin in the Diagnosis and Management of Community-Acquired Pneumonia in Hospitalized Adults
}

\author{
Justin J Choi, MD ${ }^{*}$, Matthew W McCarthy, MD, FACP1, Matthew S Simon, MD, MSc ${ }^{2,3}$ \\ Arthur T Evans, MD, MPH'1 Wesley H Self, MD, MPH${ }^{4}$, Marshall J Glesby, MD, PhD2,3
}

${ }^{1}$ Division of Hospital Medicine, Department of Medicine, New York-Presbyterian-Weill Cornell Medical Center, New York, New York; ${ }^{2}$ Division of Infectious Diseases, Department of Medicine, New York-Presbyterian-Weill Cornell Medical Center, New York, New York; ${ }^{3}$ Department of Healthcare Policy \& Research, New York-Presbyterian Hospital-Weill Cornell Medicine, New York, New York; ${ }^{4}$ Department of Emergency Medicine, Vanderbilt University Medical Center, Nashville, Tennessee.

ommunity-acquired pneumonia (CAP) accounts for more than 1.5 million adult hospitalizations and 100,000 deaths each year in the United States. ${ }^{1}$ Antibiotic overuse in the hospital setting is an important contributor to the rise of antibiotic resistance, prompting increased efforts to limit inappropriate antibiotic use in hospitals. ${ }^{2}$ Procalcitonin, a precursor of the hormone calcitonin, is upregulated in bacterial infections and downregulated in viral infections. The US Food and Drug Administration has approved it as a serum biomarker to assist clinicians with decisions about using antibiotics. ${ }^{3}$

There is no consensus on how to best use procalcitonin in the management of CAP. We provide a practical update that includes a review of recent literature, added secondary analysis, and expert opinion surrounding the use of procalcitonin in the diagnosis and management of CAP in hospitalized adults.

\section{INITIATION OF ANTIBIOTICS}

Initial procalcitonin levels do not sufficiently exclude bacterial etiologies of CAP to withhold antibiotic prescription safely. The largest diagnostic accuracy study of procalcitonin in the diagnosis of CAP was a subanalysis of the Etiology of Pneumonia in the Community Study. ${ }^{4}$ A total of 1,735 adults hospitalized with CAP received procalcitonin testing along with systematic pathogen testing. The area under the receiver operating characteristic curve for procalcitonin in discriminating bacterial pathogens from viral pathogens was $0.73(95 \% \mathrm{Cl}, 0.69-0.77)$. A procalcitonin cut-off of $0.1 \mathrm{ng} / \mathrm{mL}$ resulted in $80.9 \%(95 \% \mathrm{Cl}, 75.3 \%$ $85.7 \%)$ sensitivity and $51.6 \%(95 \% \mathrm{Cl}, 46.6 \%-56.5 \%)$ specificity for identification of any bacterial pathogen.

In a secondary analysis of this study, we calculated multilevel likelihood ratios (LRs) for ranges of procalcitonin values to determine the diagnostic accuracy of procalcitonin in distinguishing bacterial from viral etiologies of CAP (Table). Multilevel LRs offer more useful diagnostic information than dichotomizing at specified cut-points. ${ }^{5}$ A procalcitonin result less than $0.1 \mathrm{ng} / \mathrm{mL}$ has a negative LR of $0.4(95 \% \mathrm{Cl}, 0.3-0.5)$, which is not low enough to

*Corresponding Author: Justin J. Choi, MD; E-mail: juc9107@med.cornell.edu; Telephone: 212-746-4071; Twitter: @JustinJWChoi

Published online first August 21, 2019.

Received: April 15, 2019; Revised: June 15, 2019; Accepted: June 21, 2019

๑) 2019 Society of Hospital Medicine DOI 10.12788/jhm.3272 rule out bacterial CAP effectively when starting with intermediate or high pretest probability. For a low result $(<0.1 \mathrm{ng} / \mathrm{mL})$ to be useful in ruling out bacterial CAP, for example having less than a $10 \%$ posttest probability of bacterial CAP, the pretest probability would have to be no greater than $22 \%$. Even then, a $10 \%$ posttest probability of bacterial CAP may still be too high for clinicians to withhold initial antibiotics. For procalcitonin values between $0.1 \mathrm{ng} / \mathrm{mL}$ and $1.0 \mathrm{ng} / \mathrm{mL}$, the probability of bacterial CAP does not change significantly, with an LR of 1.0 (95\% Cl, 0.8-1.3). Procalcitonin values up to $5 \mathrm{ng} / \mathrm{mL}$ reach a modest positive $\mathrm{LR}$ of $2.3(95 \% \mathrm{Cl}, 0.8-4.3)$. Very high values, such as those $>10 \mathrm{ng} / \mathrm{mL}$, yield a positive LR of $5.5(95 \% \mathrm{Cl}, 3.2-9.7)$, are potentially useful in decisions to initiate antibiotics in situations of very low pretest probability of bacterial CAP. For example, a 9\% pretest probability of bacterial CAP is likely below many physicians' threshold for starting antibiotics. A procalcitonin of $12 \mathrm{ng} / \mathrm{mL}$ in this patient would increase the posttest probability to $35 \%$, a value that would prompt many physicians to initiate antibiotics.

Overall, there is insufficient evidence to support the use of procalcitonin as a stand-alone test for ruling out bacterial CAP, limiting its use in withholding antibiotics in patients with suspected bacterial CAP.

\section{DISCONTINUATION OF ANTIBIOTICS}

While initial procalcitonin measurements may not affect the initial antibiotic treatment decision, procalcitonin levels thereafter can guide the duration of therapy. A meta-analysis of procalcitonin-guided treatment in patients with upper or lower respiratory tract infection (LRTI) showed that procalcitonin guidance reduces antibiotic exposure and antibiotic-related adverse effects and improves survival, albeit a small absolute mortality difference of 1.4 percentage points, primarily observed in the intensive care unit setting. ${ }^{6}$ Most patients included in this meta-analysis were diagnosed with LRTI (91\%), and CAP was the predominant subtype of LRTI (43\%). The main effect of procalcitonin guidance for patients with CAP was earlier discontinuation of antibiotic treatment. Procalcitonin-guided algorithms in these trials discouraged, or strongly discouraged, antibiotics if procalcitonin was $<0.25 \mathrm{ng} / \mathrm{mL}$ or $<0.1 \mathrm{ng} / \mathrm{mL}$, respectively. In addition, serial procalcitonin measurements were used to guide discontinuation of antibiotics if procalcitonin dropped below 0.25 $\mathrm{ng} / \mathrm{mL}$, or by $80 \%$ to $90 \%$ from the peak value. This approach safely shortened the duration of therapy in patients with CAP. 


\begin{tabular}{|c|c|c|c|}
\hline $\begin{array}{l}\text { PCT Levels } \\
\text { (ng/mL) }\end{array}$ & $\begin{array}{l}\text { Bacterial CAP } \\
\text { (n) }\end{array}$ & $\begin{array}{l}\text { Viral CAP } \\
\text { (n) }\end{array}$ & $\begin{array}{l}\text { Likelihood Ratio } \\
\quad(95 \% \mathrm{Cl})\end{array}$ \\
\hline$<0.1$ & 45 & 211 & $0.4(0.3-0.5)$ \\
\hline $0.1-1.0$ & 73 & 125 & $1.0(0.8-1.3)$ \\
\hline $0.10-0.24$ & 33 & 59 & $1.0(0.7-1.4)$ \\
\hline $0.25-0.49$ & 20 & 28 & $1.2(0.7-2.1)$ \\
\hline $0.50-0.99$ & 20 & 38 & $0.9(0.5-1.5)$ \\
\hline $1.0-2.5$ & 26 & 31 & $1.5(0.9-2.4)$ \\
\hline $1.00-1.49$ & 14 & 15 & $1.6(0.8-3.3)$ \\
\hline $1.50-2.49$ & 12 & 16 & $1.3(0.6-2.7)$ \\
\hline $2.5-5$ & 23 & 17 & $2.3(1.3-4.3)$ \\
\hline 5-10 & 21 & 10 & $3.6(1.7-7.6)$ \\
\hline$>10$ & 48 & 15 & $5.5(3.2-9.7)$ \\
\hline Total & 236 & 409 & \\
\hline
\end{tabular}

Data extracted from Self WH, et al. Procalcitonin as a Marker of Etiology in Adults Hospitalized With Community-Acquired Pneumonia. Clin Infect Dis. 2017;65(2):183-190. ${ }^{4}$

Abbreviations: CAP, community acquired pneumonia, $\mathrm{PCT}$, procalcitonin

There are several limitations in the interpretation and generalizability of this meta-analysis. There is large heterogeneity across the included clinical trials in design, procalcitonin protocols, clinical setting, and respiratory infection type, including bronchitis, acute exacerbation of chronic obstructive pulmonary disease (AECOPD), and CAP. Results were consistent only in one moderate to high quality randomized trial specifically studying CAP in the inpatient setting. ${ }^{7}$ Additionally, most of these trials were conducted in Europe. Antibiotic prescribing practices may be different in the US, and prescribing practices on both continents may have changed over the years with greater awareness and appreciation of antibiotic stewardship.

\section{PROCALCITONIN-GUIDED ALGORITHMS}

The ProACT trial, the largest randomized, US multicenter trial to evaluate a procalcitonin-based algorithm to assist with antibiotic decision making, included over 1,600 emergency department patients at 14 academic medical centers. ${ }^{8}$ Procalcitonin guidance in this trial did not reduce antibiotic exposure compared with usual care for patients with suspected LRTI. However, its applicability to the practice of hospitalists and the inpatient setting is limited. First, only $48 \%$ of the study participants required hospitalization. Second, this study included all LRTIs, with CAP comprising just $20 \%$ of all final diagnoses. Third, the average number of antibiotic days during hospitalization for CAP was short in both groups (3.9 days in the procalcitonin group and 4.1 days in the usual care group). This relatively short antibiotic duration makes it difficult for any intervention to decrease antibiotic days meaningfully.

In a prepost controlled intervention study for inpatients at a single US tertiary care hospital, procalcitonin guidance in hospitalized patients safely reduced antibiotic use in LRTI, specifically for the discontinuation of antibiotics. ${ }^{9}$ The greatest ben- efit of procalcitonin guidance in antibiotic discontinuation was found in patients with AECOPD and patients with an admitting diagnosis of CAP, but with mild illness and low procalcitonin. Although this prepost study suggested a safe reduction of antibiotic use due to implementation of procalcitonin guidance, the lack of randomization and the absence of a contemporaneous control group are important limitations. Given the mixed findings on the effectiveness of procalcitonin guidance for hospitalized CAP patients in the US, further investigation will be needed with large clinical trials in the inpatient setting for CAP.

\section{CONCLUSIONS}

There is insufficient evidence to support the use of serum procalcitonin to withhold initial antibiotics in patients with a clinical syndrome consistent with bacterial CAP. However, the literature supports the use of procalcitonin for the early discontinuation of antibiotics for cases in which the probability of bacterial CAP is low, and procalcitonin remains below $0.1 \mathrm{ng} / \mathrm{mL}$ (Figure).

Serial measurements of procalcitonin every one to two days may also be used when clinical uncertainty remains regarding the need for antibiotics. Very low or significantly decreasing procalcitonin levels in patients with CAP and no identified bacterial pathogen likely indicate the infection was not bacterial, or was bacterial but has now been adequately treated with antibiotics. For cases of proven bacterial etiology or high clinical suspicion of bacterial CAP, there is insufficient evidence to recommend the early discontinuation of antibiotics based on procalcitonin levels short of the recommended five-day course according to current guidelines. ${ }^{10}$ Future clinical trials are needed to determine if procalcitonin guidance can safely decrease the duration of antibiotic therapy for confirmed bacterial CAP to less than five days.

There are discrepancies between the apparent test characteristics of procalcitonin and the recommended antibiotic decisions in many procalcitonin algorithms. For example, algorithms discourage antibiotics when procalcitonin values are $0.1-0.24 \mathrm{ng} / \mathrm{mL}$, and encourage (or even strongly encourage) antibiotic use for higher procalcitonin values of 0.25-1.0 ng/ $\mathrm{mL}$. However, the LRs for these ranges are identical and are approximately 1.0 (Table), suggesting that decision-making should be similar across the entire procalcitonin range of 0.1 to 1.0. Future clinical trials should study revised algorithms with different cut-points, including the thresholds found in our secondary analysis of multilevel LRs. Until then, we believe there is insufficient evidence to deviate from current antibiotic decision recommendations at the traditional cut-points.

While procalcitonin is an imperfect biomarker for discriminating bacterial and nonbacterial etiologies of CAP, it may still provide helpful information for the hospitalist in antibiotic decision-making in the same way we apply other commonly used clinical variables such as fever, white blood cell count, band count, and the pattern of infiltrate in chest imaging.

Procalcitonin should be interpreted cautiously in certain populations in which it has not been extensively studied (eg, immunocompromised) or in noninfectious conditions that may elevate procalcitonin, such as major physiologic stress (eg, surgery, trauma, burns) and end-stage renal disease. ${ }^{12-14}$ Further 


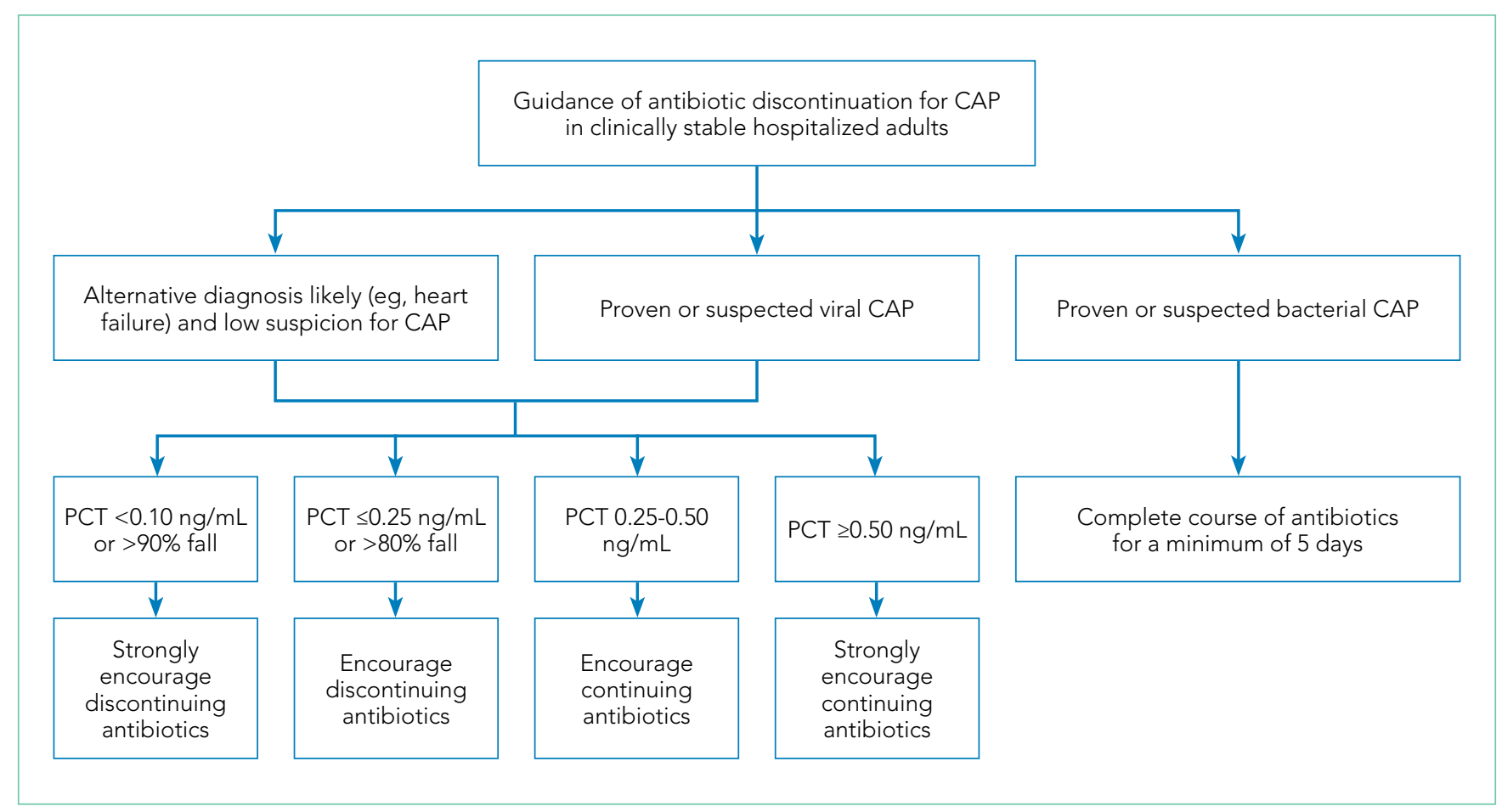

FIG. Procalcitonin Guidance for Antibiotic Discontinuation in Hospitalized Adults with CAP

The cut-off values and thresholds used in this algorithm are adapted from those used in the clinical trials included in the 2017 Cochrane review meta-analysis. ${ }^{6}$

Abbreviations: CAP, community acquired pneumonia, PCT, procalcitonin.

investigation is needed to determine the efficacy and safety of procalcitonin-guided antibiotic therapy in these populations.

\section{RECOMMENDATIONS}

- Based on currently available data, a low procalcitonin value should not be used as a stand-alone test to withhold antibiotics in a patient with CAP.

- Serum procalcitonin measurements may help guide the early discontinuation of antibiotics for patients who the treating clinician judges the risks of bacterial etiology and clinical deterioration to be low.

- Interpret procalcitonin cautiously in immunocompromised patients, undergoing severe physiologic stress, or have underlying end-stage renal disease.

- Serum procalcitonin serves as an adjunct to, rather than a substitute for, clinical judgment.

Disclosures: Dr Choi, Dr Evans, and Dr Glesby have nothing to disclose. Dr Self reports receiving prior research funding from BRAHMS/Thermo-Fisher and BioMerieux for studies on procalcitonin. Dr Self reports personal fees from Inflammatix, grants from Axis Shield, Rapid Pathogen Screening, and BioMerieux, all outside the submitted work. Dr McCarthy reports receiving research funding from Allergan outside the submitted work. Dr Simon reports receiving consulting fees from Roche Diagnostics.

\section{References}

1. Ramirez JA, Wiemken TL, Peyrani $P$, et al. adults hospitalized with pneumonia in the united states: incidence, epidemiology, and mortality. Clin Infect Dis. 2017:65(11):1806-1812. https://doi.org/10.1093/cid/cix647.

2. Hecker MT, Aron DC, Patel NP, Lehmann MK, Donskey CJ. Unnecessary use of antimicrobials in hospitalized patients: current patterns of misuse with an emphasis on the antianaerobic spectrum of activity. Arch Intern Med. 2003;163(8):972-978. https://doi.org/10.1001/archinte.163.8.972.

3. Rhee C. Using procalcitonin to guide antibiotic therapy. Open Forum Infect Dis. 2017;4(1):ofw249. https://doi.org/10.1093/ofid/ofw249.

4. Self WH, Balk RA, Grijalva CG, et al. Procalcitonin as a marker of etiology in adults hospitalized with community-acquired pneumonia. Clin Infect Dis. 2017;65(2):183-190. https://doi.org/10.1093/cid/cix317.

5. Straus SE, Richardson WS, Glasziou P, Haynes RB. Evidence-Based Medicine: How to Practice and Teach It (4th Edition). Fourth Edition ed. London, England: Elsevier Churchill Livingstone; 2010

6. Schuetz $P$, Wirz $Y$, Sager R, et al. Procalcitonin to initiate or discontinue antibiotics in acute respiratory tract infections. Cochrane Database Syst Rev. 2017;10:CD007498. https://doi.org/10.1164/rccm.200512-1922OC.

7. Christ-Crain M, Stolz D, Bingisser R, et al. Procalcitonin guidance of antibiotic therapy in community-acquired pneumonia: a randomized trial. Am J Respir Crit Care Med. 2006;174(1):84-93. https://doi.org/10.1056/NEJMoa1802670.

8. Huang DT, Yealy DM, Filbin MR, et al. Procalcitonin-guided use of antibiotics for lower respiratory tract infection. N Engl J Med. 2018;379(3):236-249. https://doi.org/10.1056/NEJMoa1802670

10. Townsend J, Adams V, Galiatsatos $P$, et al. Procalcitonin-guided antibiotic therapy reduces antibiotic use for lower respiratory tract infections in a United States medical center: results of a clinical trial. Open Forum Infect Dis. 2018:5(12):ofy327. https://doi.org/10.1093/ofid/ofy327.

11. Mandell LA, Wunderink RG, Anzueto A, et al. Infectious Diseases Society of America/American Thoracic Society consensus guidelines on the management of community-acquired pneumonia in adults. Clin Infect Dis. 2007;44 Suppl 2:S27-S72. https://doi.org/10.1086/511159

12. Seoane L, Pértega S, Galeiras R, Astola I, Bouza T. Procalcitonin in the burn unit and the diagnosis of infection. Burns. 2014;40(2):223-229. https://doi. org/10.1016/j.burns.2013.11.018.

13. Dahaba AA, Rehak PH, List WF. Procalcitonin and C-reactive protein plasma concentrations in nonseptic uremic patients undergoing hemodialysis. Intensive Care Med. 2003:29(4):579-583. https://doi.org/10.1007/s00134-003-1664-8.

14. Ghabra H, White W, Townsend M, Boysen P, Nossaman B. Use of biomarkers in the prediction of culture-proven infection in the surgical intensive care unit. J Crit Care. 2019;49:149-154. https://doi.org/10.1016/j.jcrc.2018.10.023.

15. Hoshino K, Irie Y, Mizunuma M, Kawano K, Kitamura T, Ishikura H. Incidence of elevated procalcitonin and presepsin levels after severe trauma: a pilot cohort study. Anaesth Intensive Care. 2017;45(5):600-604. https://doi. org/10.1177/0310057X1704500510. 